$$
\begin{aligned}
& S \text { sciendo International Conference KNOWLEDGE-BASED ORGANIZATION } \\
& \begin{array}{lll}
\text { Vol. XXV No } 3 & 2019
\end{array}
\end{aligned}
$$

\title{
PECULIARITIES REGARDING SATELLITE NAVIGATION ON THE TERRITORY OF ROMANIA
}

\author{
Vlad-Cosmin VASILE*, Corina NAFORNIȚA**, Monica BORDA*, Teodor MITREA* \\ * Technical University, Cluj-Napoca, Romania \\ ** Politehnica University, Timişoara, Romania \\ vladut.vasile@yahoo.com, corina.nafornita@upt.ro, \\ Monica.Borda@com.utcluj.ro,mitrea_theodor@yahoo.co.uk
}

\begin{abstract}
This paper describes the particularities of satellite navigation on the territory of Romania in search of solutions to improve the accuracy of these systems. The performance of a Global Navigation Satellite System (GNSS) is influenced by many factors, including distortion of the signal, the influence of the ionosphere and the troposphere, multipath propagation. Some of these factors depend on the geographical position and the environment in which the navigation system is used. Moreover, Romania is located at the border of coverage of two Satellite Based Augmentation Systems (SBAS) - European Geostationary Navigation Overlay Service (EGNOS) and System for Differential Corrections and Monitoring (SDCM) which leads to some peculiarities regarding satellite navigation.
\end{abstract}

\section{Keywords: satellite navigation, SBAS, Dilution of Precision}

\section{Introduction}

A Global Navigation Satellite System (GNSS) is a system that calculates the geospatial position of objects using the signals received from the navigation satellites. The most popular GNSS is Global Positioning System (GPS). Positioning accuracy of a GNSS can be much improvedby Satellite Based Augmentation Systems (SBAS). These systems improve the data provided by GNSSwith the help of a network of monitoring stations and geostationary satellites [1].

The paper is organized as follows: section 2 describes satellite based augmentation systems; in section 3 are made simulations that highlight how two of these systems can improve localization accuracy, taking an observation point in Romania, for 24 hours, while the last section concludes the paper.

\section{Satellite Based Augmentation systems}

Globally, there are several satellite based augmentation systems: European Geostationary Navigation Overlay Service (EGNOS) in Europe, Wide Area Augmentation System in United States, Multi-Function Satellite Augmentation System (MSAS) in Japan, System for Differential Corrections and Monitoring (SDCM) in the Russian Federation, GPS and GEO Augmented Navigation System (GAGAN) in India.

All these systems have a spatial component made up of geostationary satellites and a terrestrial component including monitoring stations. The coverage of these systems depends on the locations where the monitoring stations are installed [2],[3],[4]. EGNOS is the European system which improves the accuracy of the US satellite navigation system (GPS) using 
geostationary satellites. This systemwill be embedded in Galileo, the future European satellite navigation system. Using EGNOS, the positioning accuracy of GPS signals is improved to less than $2 \mathrm{~m}$, covering most European countries [5].

WAAS is a SBAS belonging to the United States that improves GPS signals using three geostationary satellites and a network of reference stations.

This system provides a positioning accuracy at meter level, covering the North American continent. WAAS operation is similar to EGNOS, using reference stations on the territory of the United StatesMexico,Canada, and Puerto Rico.

The Japanese satellite navigation enhancing system, MSAS, consists of two geostationary satellites and 8 reference stations located in Japan, Hawaii and in Australia.

GAGAN, The Indian Navigation Enhancement System, has 3 geostationary satellites and 15 reference stations located on the territory of India. Because this system is situated in an area where scintillation is taking place, the positioning accuracy of this system is not at the same level with that offered by WAAS and EGNOS.The coverage area includes all Indian territory [6].

The Russian Federation already owns a GNSS - GLObal NAvigation Satellite System (GLONASS). This system is modernized withSDCM - a system under development in the Russian Federation.The spatial component is made up of three geostationary satellites and the terrestrial component is under implementation.

SDCM differs from other SBAS by a very important feature:it is built as a SBAS that provides corrections and integrity messages based on both GLONASS and GPS signals, while other SBASs use only GPS signals.

\section{Improving positioning accuracy}

Romania is located at the border of coverage of two SBAS - EGNOS and SDCM. Due to its geographical location, from Romania we will be able to track geostationary satellites belonging to both systems.

Recent studies have shown that in the countries at the boundary of the coverage area of EGNOS, estimates of the system performance are optimistic, with significant degradation in areas with low visibility or in urban areas [7], [8].

Moreover, in the case of Finland - another country which is at the limit of the EGNOS and SDCM coverage areas - studies conducted by the Finnish Geospatial Research Institute have shown that, in some situations, the Russian system offers better precision than the European one [8].

When estimating the position of an object, the navigation system puts togetherthe information obtained from the satellites in the area of visibility.

Thus, the errors that affect this information are combined, getting a positioning error. The relationship between the mean distance error and the positioning error is represented by a dimensionless single number named Dilution of Precision (DOP) or Geometric Dilution of Precision (GDOP).

DOP can be expressed as a number of separate measurements: horizontal dilution of precision (HDOP), vertical dilution of precision (VDOP), position (3D) dilution of precision (PDOP) and time dilution of precision (TDOP) [9]. A value less than 1 of this parameter is ideal, between 1 and 2 are considered excellent and between 2 and 5 good.

Since the Russian system provide corrections and integrity messages for both GPS and GLONASS signals, we compared the DOP values in three cases, taking an observation point in Romania (Figure 1), for 24 hours.

First, we illustrated the DOP values using GPS satellitesas shown in Figure 2, then we added information from two EGNOS geostationary satellites, the result being represented in Figure 3, and finally we used the correction information of an SDCM 
satellite, obtaining the results from Figure 4. For this purpose,we used "GNSS Mission
Planning simulator" [10], offered free by Navmatix.
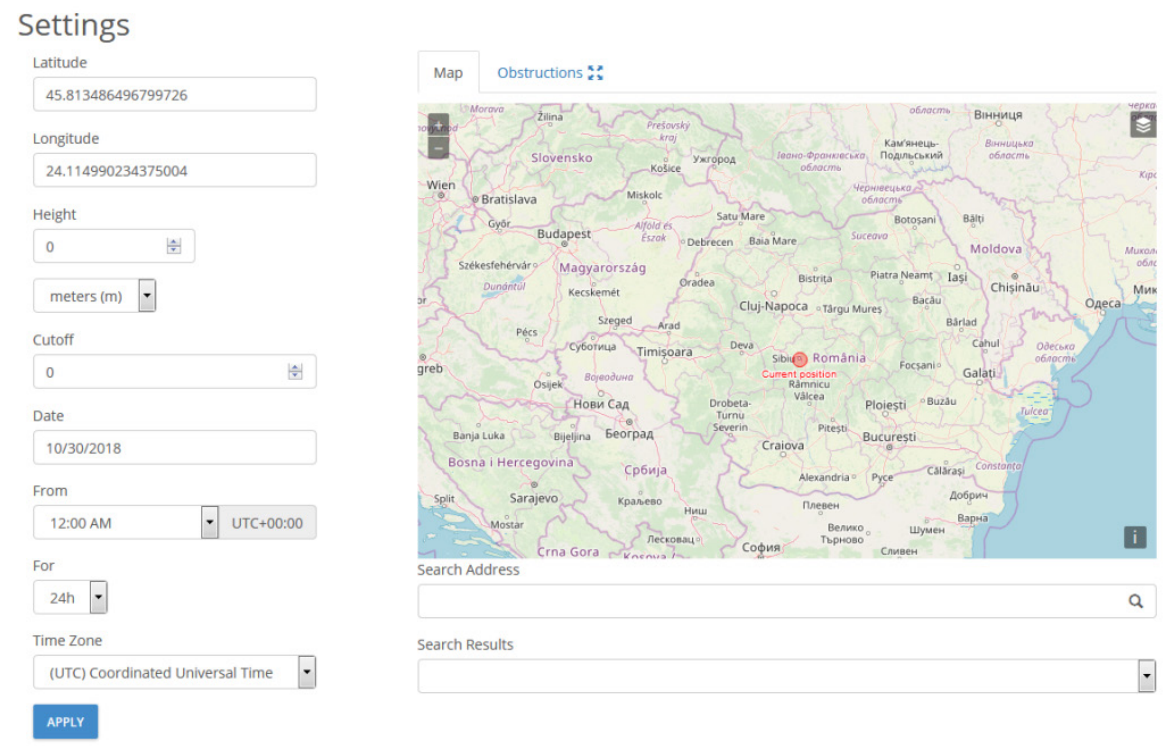

Figure 1:Selecting the observation point using "GNSS Mission Planning simulator"

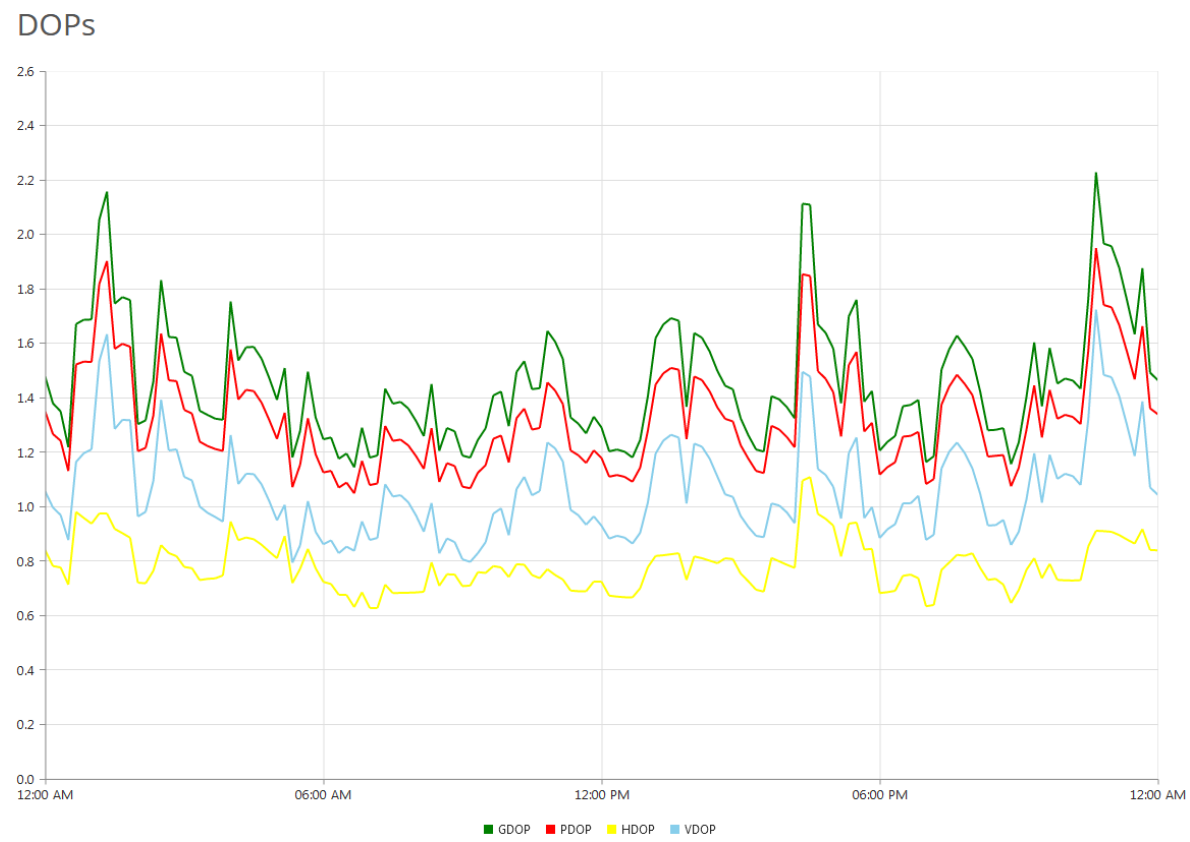

Figure 2:DOP values for GPS over 24 hours (Romania,October30, 2018)

From the analysis of this figure it can be seen thatDOP values are excellent for most of the time.
However, there are a few short periods of time in which DOP values are greater than 2. 


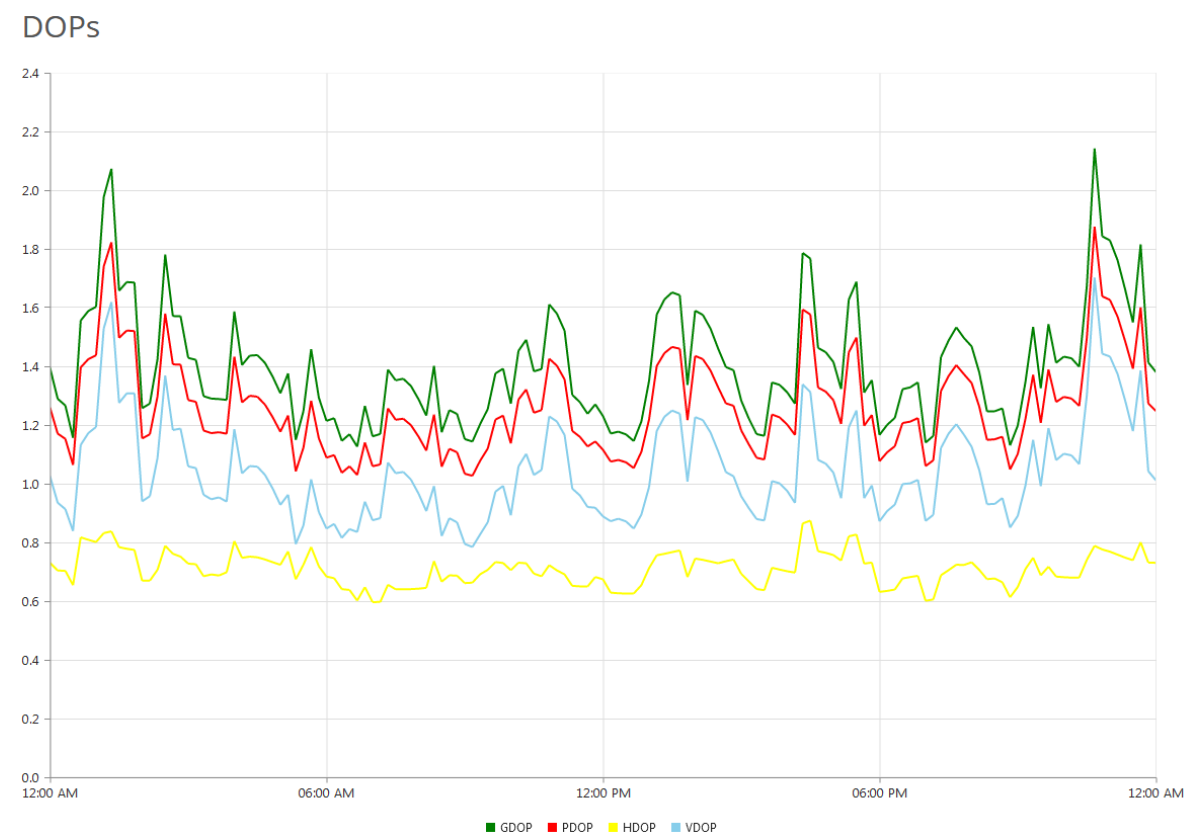

Figure 3:DOP values for GPS and EGNOS over 24 hours (Romania,October30, 2018)

Comparing the diagrams obtained in Figures 2 and 3 , we notice a slight improvement in DOP values.

$$
\text { DOPS }
$$

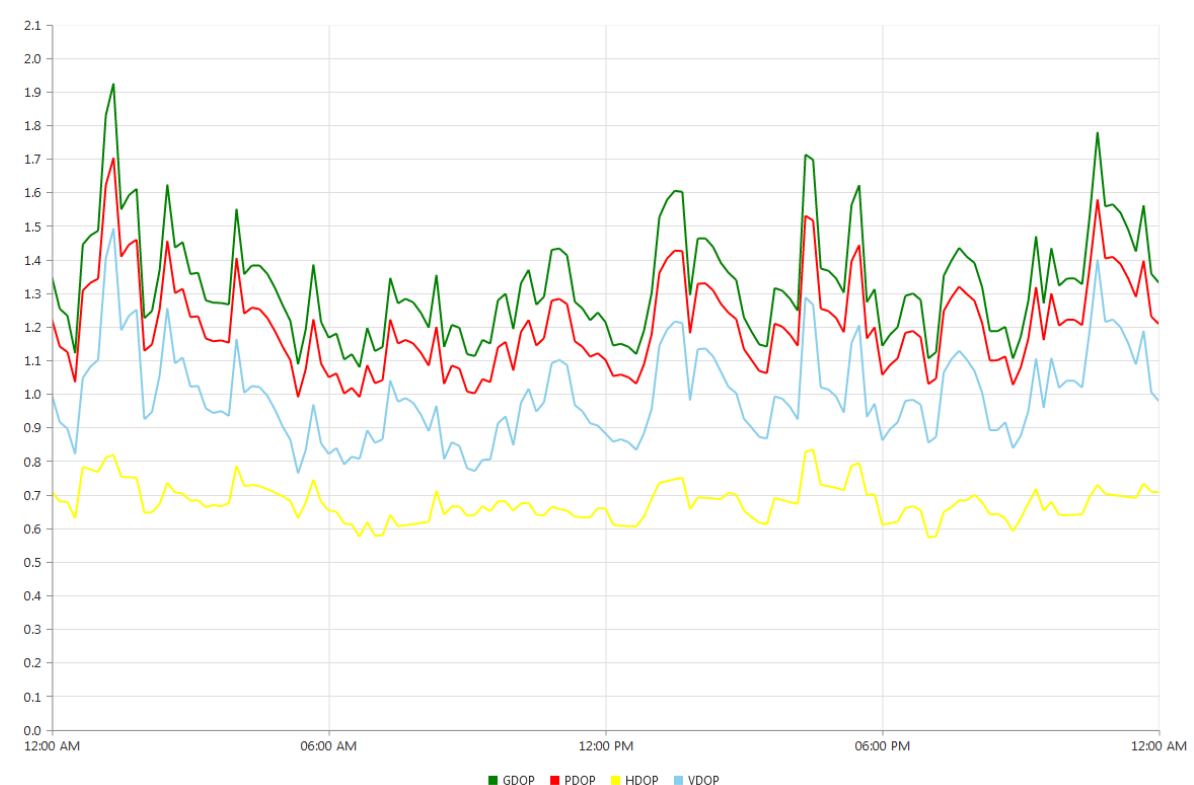

Figure 4:DOP values for GPS, EGNOS and 1 SDCM geostationary satellite over 24 hours (Romania,October30, 2018)
Analyzing the last chart, we find that, when we use corrections information provided by the Russian satellite, the improvement of the DOP values becomes more consistent, obtaining excellent values over the entire
This time, we have even fewer moments in time when the DOP values exceed the value of 2 . period of time.

\section{Conclusions}

Romania is located at the border of coverage of two Satellite Based Augmentation Systems - EGNOS and 
SDCM, which leads to some peculiarities regarding satellite navigation. In this paper, we studiedhow DOP values change when we use information from both navigation enhancement systems.

We compared the DOP values in three cases, taking an observation point in Romania, for 24 hours. First, we illustrated the DOP values using only GPS satellites, then we added information from two EGNOS geostationary satellites and finally,we used the information from an SDCM satellite.We noticed that the DOP values are improved whenwe use information from both navigation enhancement systems, this leading to the idea that the accuracy of positioning will be also improved. Moreover, this assumption can be true not only for Romania, but for all locations at the boundary of two Satellite Based Augmentation Systems.

\section{References}

[1] Peter J.G. Teunissen, Oliver Montenbruck (Eds.), Springer Handbook of Global Navigation Systems, Springer Nature, 2017.

[2] Vlad-Cosmin Vasile, Corina Nafornita, Monica Borda, Comparative Study of Satellite Navigation Systems, International Symposium on Electronics and Telecommunications (ISETC), Timisoara, Romania, November, 2018.

[3] Vlad-Cosmin Vasile, Georgiana Magu, Romeo Cosnita, Corina Nafornita, AlexandruIsar, Monica Borda, EGNOS Performance Improvements Using Monitoring Stations in Romania, International Symposium on Electronics and Telecommunications (ISETC), Timisoara, Romania, November, 2018.

[4] Corina Nafornita et al., Romania Monitoring Station Network to Support EGNOS Services in Eastern Europe, International Symposium on Electronics and Telecommunications (ISETC), Timisoara, Romania, November, 2018.

[5] European GNSS Agency, EGNOS Safety of Life (SoL) service definition document, ISBN 978-92-9206-028-2, 2016.

[6] Joint ACAC/ICAO MID workshop on GNSS, GAGAN - extension to the Gulf Region, November, 2017.

[7] Mohammad Zahidul H. Bhuiyan, Heidi Kuusniemi, Auryn Soderini, Salomon Honkala, Simo Marila, Performance of EGNOS in North-East European Latitudes, International Technical Meeting of Institute of Navigation,California, U.S.A., January, 2017.

[8] Simo Marila, Mohammad Zahidul H. Bhuiyan, Jaakko Kuokkanen, Hannu Koivula, Heidi Kuusniemi, Performance Comparison of Differential GNSS, EGNOS and SDCM in Different User Scenarios in Finland, European Navigation Conference (ENC), Helsinki, Finland, May-June, 2016.

[9] https://en.wikipedia.org/wiki/Dilution_of_precision_(navigation),Wikipedia, Dilution of precision.

[10] http://gnssmissionplanning.com/, GNSS mission planning, Navmatix. 